\title{
EXPANSION PLANNING OF ELECTRICAL NETWORKS USING LINEAR PROGRAMMING
}

\author{
By \\ Saleh Alghamdi \\ College of Technology at Al-Baha \\ P.O.Box 6, Kingdom of Saudi Arabia \\ Sa_alghamdi@hotmail.com
}

\begin{abstract}
The paper proposes an approach suitable for expansion planning of electrical transmission, subtransmission and primary distribution networks.

The proposed approach is based on d.c. load flow and linear programming techniques in order to handle the overall expansion planning problem as an optimization problem. Linear programming solution gives the would-beselected line, that causes maximum reduction in the cost function. Successively solving the modified model after adding the most effective line, which having the largest overload to existing network, leads to the optimum design of the electrical network at a time horizon.

Two case studies have been considered and the results are presented to illustrate the potentials of the proposed approach

Keywords: Transmission networks, Expansion planning, D.C. load flow and Linear programming.

\section{INTRODUCTION}

Due to the growing growth of electric demand, electric power systems are continuously confronted with several decisions regarding the present operation of the power system components (generation, transmission and distribution), the preparation of adequate conditions for its operation in the near future, and the reinforcements of its present structure to meet the future load. These decisions are classified into either "real-time operations" or "system planning," [1]. System planning consists of two separate activities namely; "expansion planning" and "operations planning".
\end{abstract}

Manuscript recevied from Dr. Saleh A. Al-Ghamdi, accepted on: 23/6/2001,

Engineering research bulletin, Vol. 24, No. 3, 2001, Minufiya University, Faculty of Engineering, Shebien El-Kom, Egypt, ISSN 1110 - 1180 
Expansion planning starts with demand forecasting of energy and capacity over the planning horizon, then, power system components are analyzed for each year of the study for economy, security and environmental impact. Though many publications are dealt with distribution planning, [2-9], a relatively fewer number is dealt with high voltage transmission planning, [911]. Electrical network planning may be divided into short-term, (static) network planning and long-term, (dynamic) network planning. Static network planning is interested in the network connection scheme for a particular future load horizon year. For a long-term planning, the planning process is divided into several horizon years in which the transit problem of each horizon year is considered. In such circumstances, one has to decide when and where to build a new transmission line?, and what type of line to build?.

From the solution viewpoint, network planning methods may be grouped into two categories: heuristic and mathematical optimization methods. The heuristic method is based on intuitive analysis. It consists of overload checking, sensitivity analysis and scheme formation. It is generally characterized by a lack of consideration of interaction between decisions of additions. Therefore, it can not guarantee mathematically an optimal solution, which is its main disadvantage. Mathematical optimization methods formulate the design requirements of network planning as an operational mathematical planning model and is solved by any optimization technique such that an optimal planning scheme is obtained satisfying all constraints, [12]. Currently, there are linear programming, dynamic programming, mixed integer programming, branch and bound technique and topology methods. They have some limitations in practical applications.

This paper proposes an efficient planning tool, based on d.c. load flow and linear programming techniques, valid for high voltage transmission networks as well as for primary distribution networks. The objective is to determine the optimal expansion planning required to upgrade an existing network according to load growth and a generation planning scheme of a time horizon so as to meet the requirement of delivering electricity economically with the required quality and reliability levels.

\section{LINEARIZED POWER FLOW EQUATIONS MODEL}

The a.c. power flow equations may be written $[13,14]$ as

$$
P_{i}=V_{i} \sum_{j \in i} V_{j}\left(G_{i j} \cos \theta_{i j}+B_{i j} \sin \theta_{i j}\right) \quad ; i=1,2, \ldots \ldots . ., N B
$$

$j \in i$ means that nodes which are directly connected to the node $\mathrm{i}$, including $\mathrm{j}$ $=\mathrm{i}$

The branch active power flow is

$$
P_{i j}=V_{i} V_{j}\left(G_{i j} \cos \theta_{i j}+B_{i j} \sin \theta_{i j}\right)
$$

For sake of simplicity; without causing large errors in computations, a.c. load flow equations (1) \& (2) are linearized by introducing the following assumptions:

1) $r_{i j} \ll x_{i j} \rightarrow r_{i j} \approx 0$, 
2) $\theta_{i j} \ll \rightarrow \cos \theta_{i j}=1 \& \sin \theta_{i j}=\theta_{i j}$, and

3) $V_{1}=V_{2}=\ldots \ldots=V_{N B}=1 p u$

So, the linearized power flow model, (d.c. load flow equations) may be deduced as

$$
\begin{aligned}
P_{i} & =\sum_{j \in i} B_{i j} \theta_{j} \quad ; i=1,2, \ldots \ldots . ., N B \\
\& & \\
P_{i j} & =\frac{\theta_{i}-\theta_{j}}{x_{i j}}
\end{aligned}
$$

Equations (3), (4) may be written in matrix form as

$$
\begin{gathered}
{[P]=[B \llbracket \theta]} \\
\text { and, } \\
{\left[P_{L}\right]=\left[B_{L} \llbracket A \rrbracket \theta\right]}
\end{gathered}
$$

\section{OVERALL MODEL FORMULATION}

Assuming an existing network consists of NB' nodes and NL' branches. In a future horizon year, the network will be expanded to satisfy the new expected demand safely and economically. Number of buses will be increased to NB nodes, and number of branches to NL branches after considering all possible lines. The net injected active power vector at the horizon year may be divided into two vectors as

$$
\left[P^{\prime}\right]+\left[P^{\prime \prime}\right]=[P]
$$

$\left[P^{\prime}\right]$ is related to the existing network such that there is no over load, whereas, $\left[P^{\prime \prime}\right]$ belongs to possible lines. Substituting about $\left[P^{\prime}\right]$ from equation (5) and about $\left[P^{\prime \prime}\right]$ using kirchoff's laws and possible lines, equation (7) becomes

$$
[B \amalg \theta]+[K]^{T}\left[P_{D}\right]=[P]
$$

The objective function will include only the transmission line cost of possible lines. Assuming that the transmission cost of possible lines is proportional to their flow and the cost coefficient is their construction investment. So, the overall optimization problem is formulated as

Minimize $Z=\left[C_{D}\right]^{T}\left|P_{D}\right|$

\section{Subject to:}

i) the equality constraints,

$$
\left[B[\theta]+[K]^{T}\left[P_{D}\right]=[P]\right.
$$


ii) and the inequality constraints,

$\llbracket\left[B_{L} \llbracket A \rrbracket \theta\right] \leq\left[P_{L}^{\max }\right]$

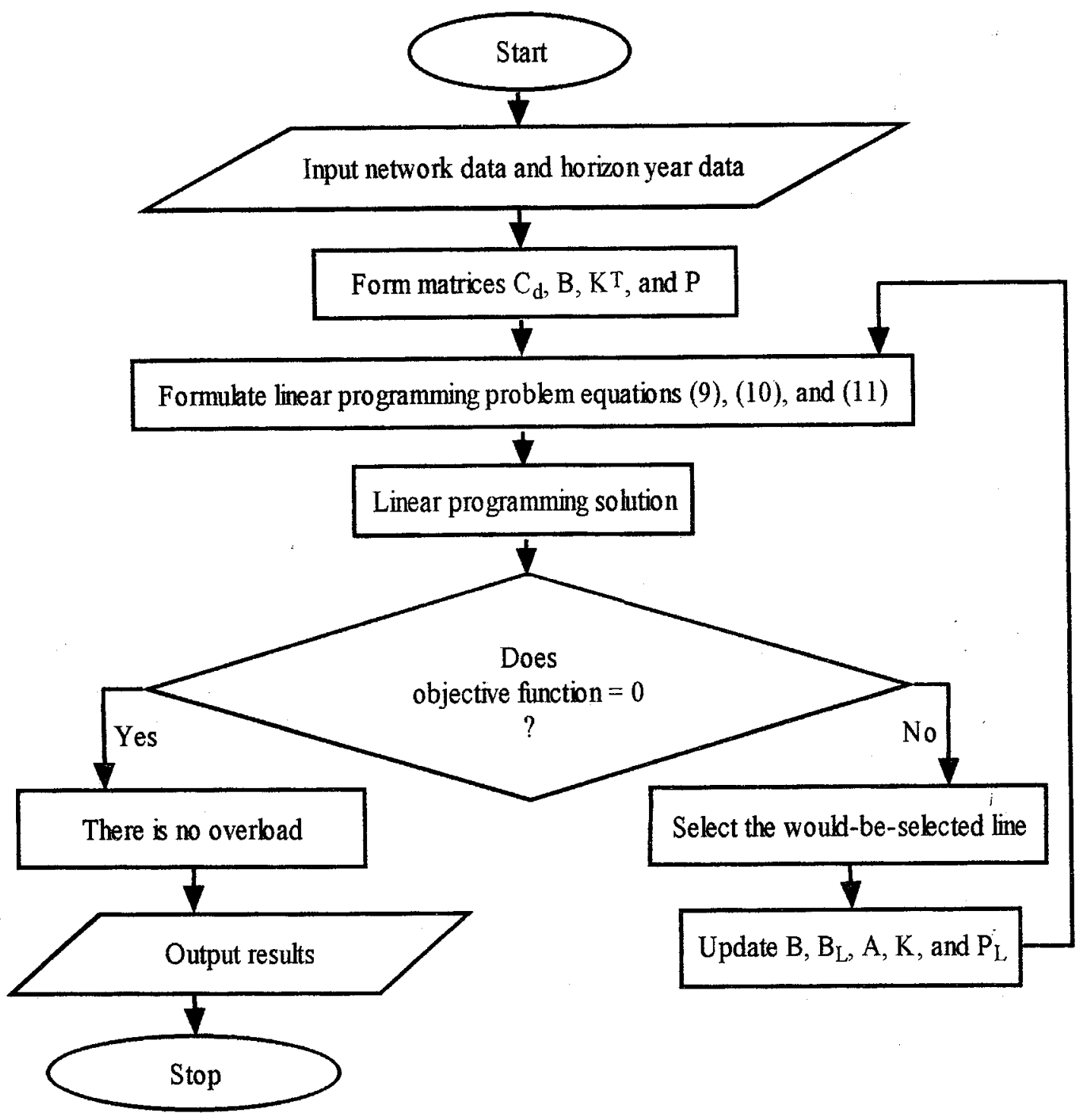

Figure 1. Flowchart of the solution procedure

\section{SOLUTION PROCEDURE}

Linear programming solution will give the state vector $[\theta]$ and the flow vector $\left[P_{D}\right]$ for possible lines. Selecting the possible line which having the maximum flow as the would-be-selected line and treating it as an existing line, will lead to the maximum reduction in the cost function. Updating matrices $[B],\left[B_{L}\right]$, and $\left[P_{L}\right]$ in the linear programming problem and solving it repeatedly until there is no any over flow (i.e. all elements of $\left[P_{D}\right]$ are zeros) 
will give the optimum network configuration at the horizon year. A flowchart of the solution procedure is given in Figure 1.

\section{CASE STUDY}

Two case studies are considered and the results are reported subsequently to demonstrate the compatibility of the developed planning approach.

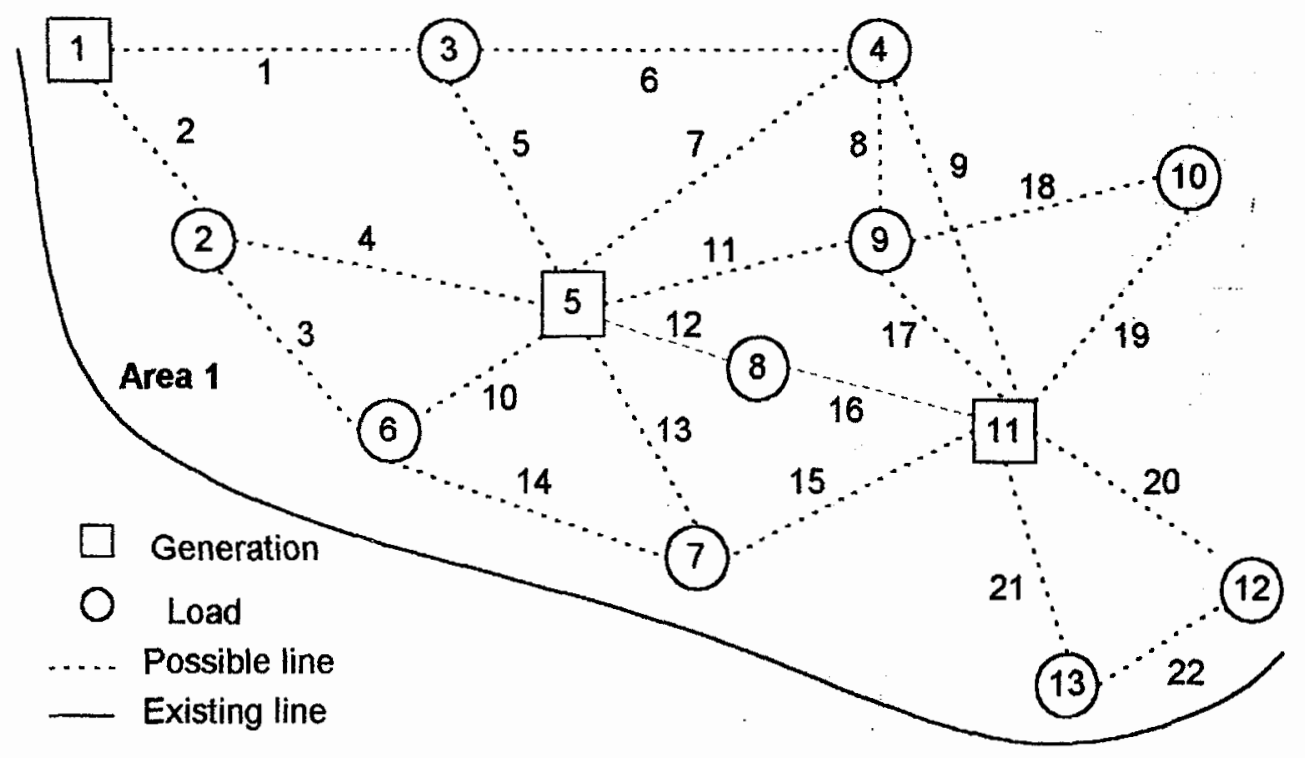

Figure 2. Right-of-ways, loads and substation locations

Table 1. Bus data of first and second stages

\begin{tabular}{|c|c|c|c|c|}
\hline \multirow[b]{2}{*}{ Bus no. } & \multicolumn{2}{|c|}{ First stage } & \multicolumn{2}{|c|}{ Second stage } \\
\hline & $\begin{array}{c}\text { Generation } \\
\text { (MW) }\end{array}$ & $\begin{array}{c}\text { Demand } \\
(\mathrm{MW})\end{array}$ & $\begin{array}{c}\text { Generation } \\
\text { (MW) }\end{array}$ & $\begin{array}{c}\text { Demand } \\
\text { (MW) }\end{array}$ \\
\hline 1 & 400 & $\cdots$ & 600 & $\ldots$ \\
\hline 2 & $\cdots$ & 150 & $\cdots$ & 190 \\
\hline 3 & $\cdots$ & 110 & $\cdots$ & 140 \\
\hline 4 & $\ldots$ & 120 & $\ldots$ & 165 \\
\hline 5 & 400 & $\cdots$ & 600 & $\cdots$ \\
\hline 6 & $\cdots$ & 130 & $\cdots$ & 170 \\
\hline 7 & $\cdots$ & 170 & $\cdots$ & 220 \\
\hline 8 & $\cdots$ & 100 & $\cdots$ & 130 \\
\hline 9 & $\ldots$ & 150 & $\cdots$ & 190 \\
\hline 10 & $\cdots$ & 130 & $\cdots$ & 170 \\
\hline 11 & 480 & $\ldots$ & 600 & $\ldots$ \\
\hline 12 & $\ldots$ & 120 & $\ldots$ & 150 \\
\hline 13 & $\cdots$ & 100 & $\cdots$ & 130 \\
\hline 14 & & & $\cdots$ & 150 \\
\hline 15 & & & $\cdots$ & 160 \\
\hline 16 & & & 500 & $\cdots$ \\
\hline 17 & & & $\cdots$ & 100 \\
\hline 18 & & & $\cdots$ & 120 \\
\hline 19 & & & $\cdots$ & 115 \\
\hline
\end{tabular}


Table 2. Line data of first and second stages

\begin{tabular}{|c|c|c|c|c|c|c|c|c|}
\hline Line & Bus & Series & Max- & Len- & First & tage & Secon & stage \\
\hline $\begin{array}{l}\text { no. } \\
\text { L }\end{array}$ & $\begin{array}{l}\text { code } \\
\mathrm{i}-\mathrm{j}\end{array}$ & $\begin{array}{c}\text { reactance } \\
\text { in }(\mathrm{pu})\end{array}$ & $\begin{array}{l}\text { capacity } \\
\text { (MW) }\end{array}$ & $\begin{array}{l}\text { in } \\
(\mathrm{km})\end{array}$ & $\begin{array}{c}\text { Exist- } \\
\text { ing } \\
\text { lines }\end{array}$ & $\begin{array}{l}\text { Right } \\
\text { of } \\
\text { way }\end{array}$ & $\begin{array}{l}\text { Exist- } \\
\text { ing } \\
\text { lines }\end{array}$ & $\begin{array}{l}\text { Right } \\
\text { of } \\
\text { way }\end{array}$ \\
\hline 1 & $1-3$ & 0.0453 & 300 & 200 & 0 & 1 & 1 & 1 \\
\hline 2 & $1-2$ & 0.0252 & 300 & 140 & 0 & 1 & 1 & 0 \\
\hline 3 & $2-6$ & 0.0371 & 300 & 80 & 0 & 1 & 1 & 0 \\
\hline 4 & $2-5$ & 0.0450 & 300 & 120 & 0 & 1 & 0 & 1 \\
\hline 5 & $3-5$ & 0.0381 & 300 & 60 & 0 & 1 & 0 & 1 \\
\hline 6 & $3-4$ & 0.0511 & 300 & 100 & 0 & 1 & 0 & 1 \\
\hline 7 & $4-5$ & 0.0522 & 300 & 160 & 0 & 1 & 1 & 0 \\
\hline 8 & $4-9$ & 0.0426 & 300 & 90 & 0 & 1 & 0 & 1 \\
\hline 9 & $4-11$ & 0.0234 & 300 & 85 & 0 & 1 & 0 & 1 \\
\hline 10 & $5-6$ & 0.0314 & 300 & 85 & 0 & 1 & 1 & 0 \\
\hline 11 & $5-9$ & 0.0450 & 300 & 110 & 0 & 1 & 1 & 0 \\
\hline 12 & $5-8$ & 0.0256 & 300 & 90 & $\overline{0}$ & 1 & 1 & 0 \\
\hline 13 & $5-7$ & 0.0301 & 300 & 80 & 0 & 1 & 1 & 0 \\
\hline 14 & $6-7$ & 0.0422 & 300 & 140 & 0 & 1 & 0 & 1 \\
\hline 15 & $7-11$ & 0.0461 & 300 & 80 & 0 & 1 & 0 & 1 \\
\hline 16 & $8-11$ & 0.0286 & 300 & 90 & 0 & 1 & 0 & 1 \\
\hline 17 & $9-11$ & 0.0286 & 300 & 90 & 0 & 1 & 1 & 0 \\
\hline 18 & $9-10$ & 0.0449 & 300 & 95 & 0 & 1 & 0 & 1 \\
\hline 19 & $10-11$ & 0,0421 & 300 & 80 & 0 & 1 & 1 & 0 \\
\hline 20 & $11-12$ & 0.0300 & 300 & 100 & 0 & 1 & 1 & 0 \\
\hline 21 & $11-13$ & 0.0271 & 300 & 105 & 0 & 1 & 1 & 0 \\
\hline 22 & $12-13$ & 0.0250 & 300 & 95 & 0 & 1 & 0 & 1 \\
\hline 23 & $13-14$ & 0.0221 & 300 & 100 & 0 & 1 & 0 & 1 \\
\hline 24 & $14-15$ & 0.0250 & 300 & 80 & & & 0 & 1 \\
\hline 25 & $15-16$ & 0.0432 & 300 & 150 & & & 0 & 1 \\
\hline 26 & $7-16$ & 0.0250 & 300 & 120 & & & 0 & 1 \\
\hline 27 & $6-16$ & 0.0247 & 300 & 55 & & & 0 & 1 \\
\hline 28 & $16-18$ & 0.0255 & 300 & 125 & & & 0 & 1 \\
\hline 29 & $16-17$ & 0.0281 & 300 & 105 & & & 0 & 1 \\
\hline 30 & $18-19$ & 0.0300 & 300 & 90 & & & 0 & 1 \\
\hline 31 & $6-19$ & 0.0351 & 300 & 135 & & & 0 & 1 \\
\hline 32 & $2-19$ & 0.0315 & 300 & 90 & & & 0 & 1 \\
\hline 33 & $15-17$ & 0.0200 & 300 & 100 & & & 0 & 1 \\
\hline
\end{tabular}

\section{i. Case study 1:}

A hypothetical geographical area, Area I, contains three electrical power sources and ten load centers is shown in Figure 2. All possible lines are shown by dotted lines. Source and demand locations and their values are tabulated in Table 1, (first stage). The right-of-ways and distances between several nodes are indicated in Table 2 . The column of right-of-way takes either the value 1 or the value 0 to indicate the possibility of installing lines between the given bus codes. Other bus and line data are written in Tables 1 and 2 . It is required to find the optimal network configuration required to supply electricity from node sources to load centers economically at a reliable level of performance. Output results of the proposed algorithm have nominated line numbers $1,2,3$, $7,10,11,12,13,17,19,19,20$ and 21 to constitute the suggested network 
configuration. The resultant network is shown in Figure 3 by solid lines seen in Area 1.

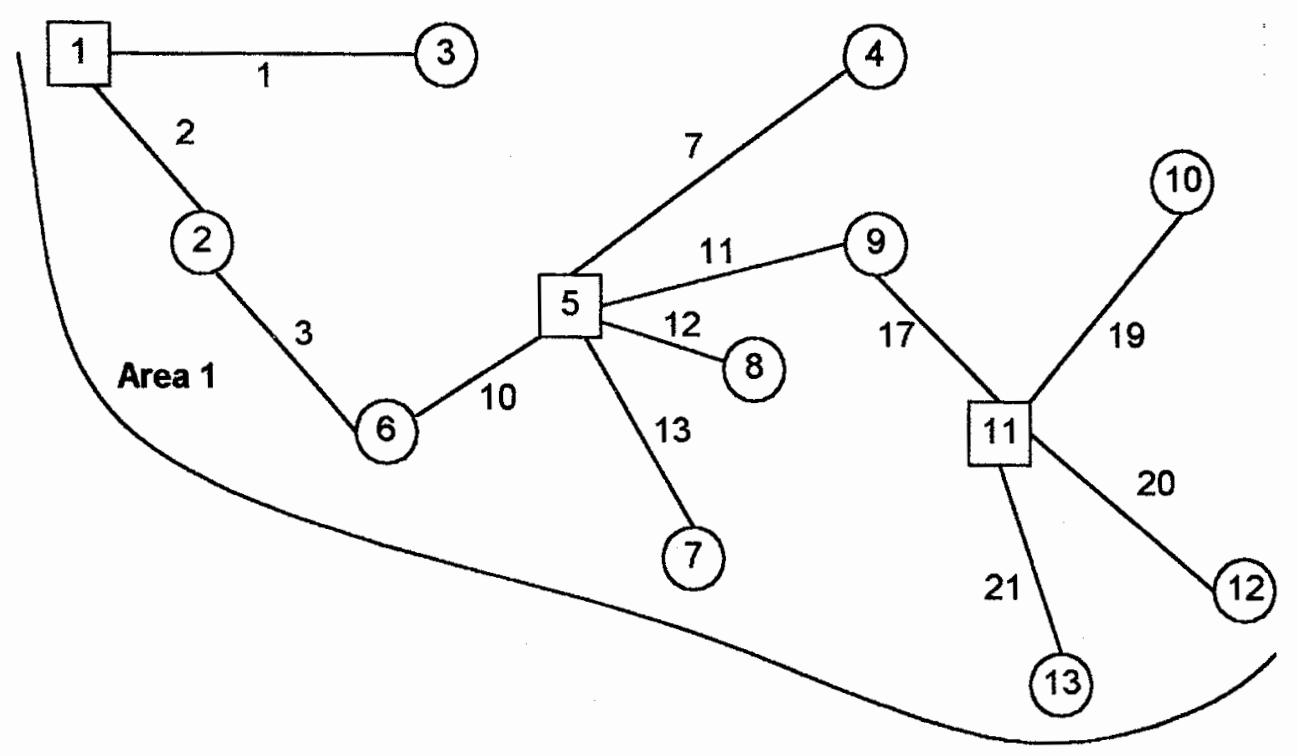

Figure 3. Optimal planning network

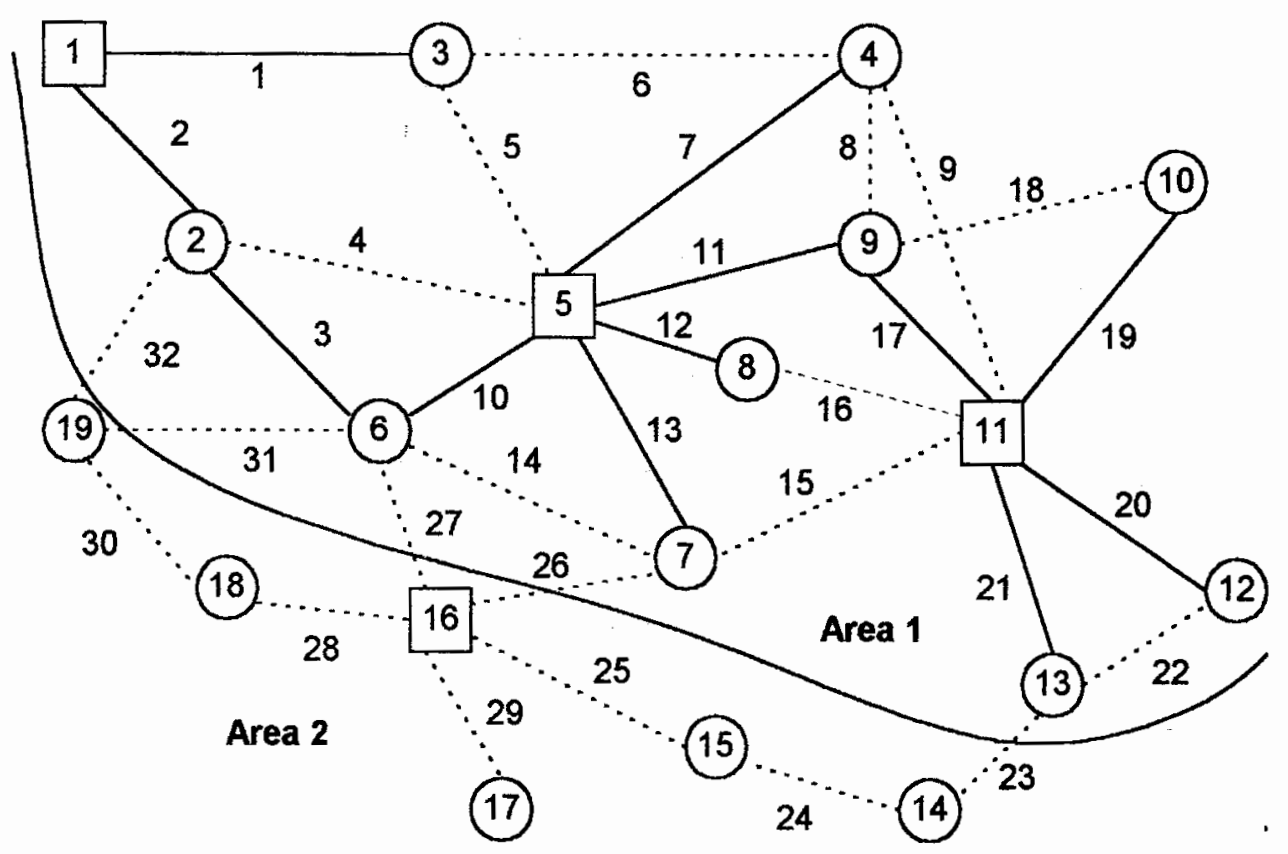

Figure 4. Existing network and new expected loads with all possible lines at horizon time 


\section{ii. Case study II:}

At the beginning of the second stage plan horizon, the existing loads are assumed to be increased by about $30 \%$ (last two columns of Table 1) in addition to the new load centers seen in Area 2 of Figure 4. All possible lines for the second stage expansion planning are indicated by dotted lines. Solid lines represent the existing network under service for the first stage. Output results have qualified line numbers $3,5,8,18,22,23,24,25,26,28,29,30$ and 32. The resultant optimal configuration is shown in Figure 5.

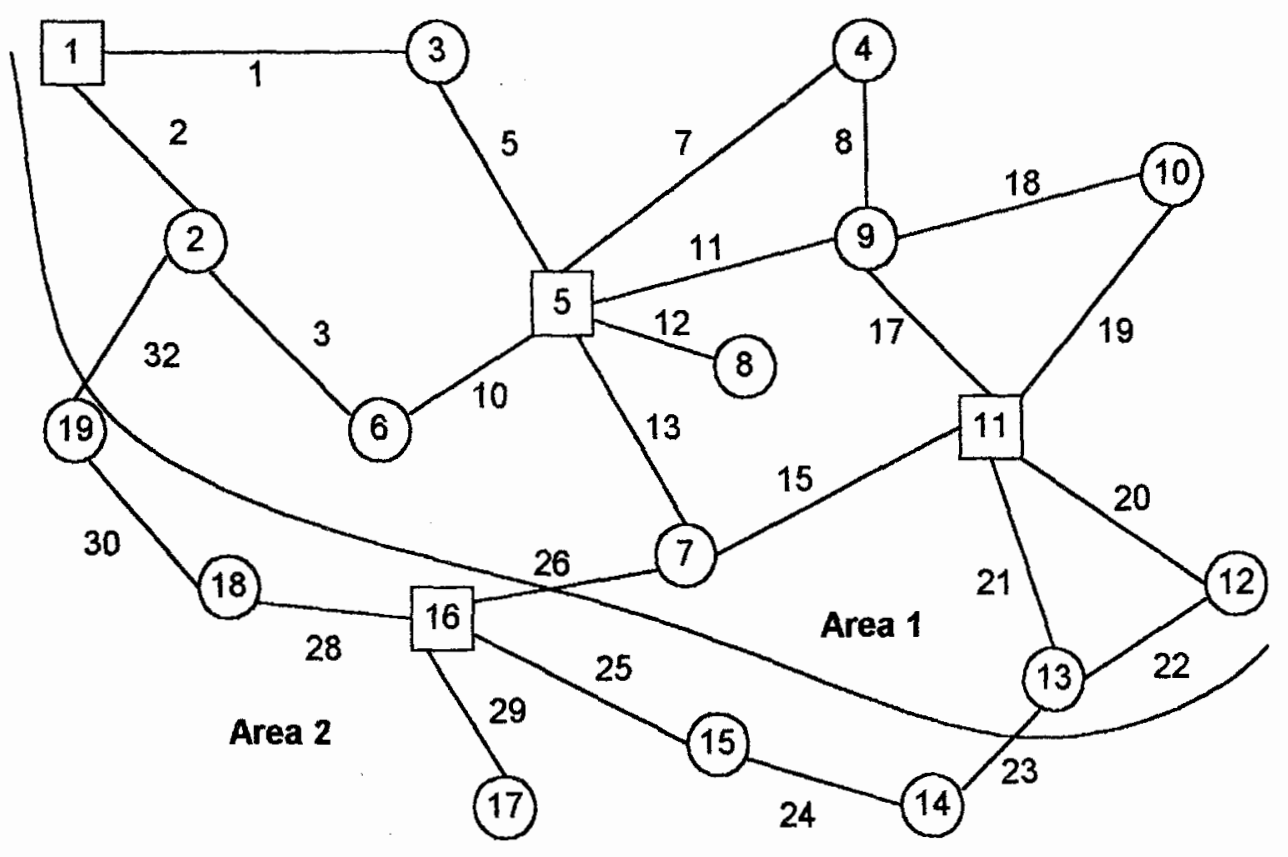

Figure 5. Optimal expansion planning at horizon year

\section{CONCLUSIONS}

A suggested multistage optimization planning method has been presented in this paper. The proposed procedure is characterized by the following advantages:

- Valid for optimum design of electrical networks as well as to upgrade the existing network according to load growth and a generation planning scheme of a time horizon.

- Valid for high voltage overhead transmission networks as well as for primary distribution networks.

- Takes into consideration technical constraints such as right-of-ways, power capacity limits and logical constraints.

- The solution procedure needs only linear programming package and there is no need to an initial load flow solution, thus the computer programming is very simple. 
Two case studies have been incorporated to illustrate the applicability, simplicity and effectiveness of the proposed algorithm. The output results have indicated that the proposed algorithm is a valuable tool to assist the system planners in reaching the optimal network configuration corresponding to a horizon year data.

\section{Glossary of Symbols:}

$N B=$ number of nodes

$N L=$ number of branches

$P_{i}=$ net active injected power at node $\mathrm{i}$

$P_{G i} ; P_{D i}=$ generator output and load at node $\mathrm{i}$

$V_{i}=$ voltage magnitude at node $\mathrm{i}$

$G_{i j}=$ real part of corresponding element of node admittance matrix

$B_{i j}=$ imaginary part of corresponding element of node admittance matrix

$\theta_{i j}=$ phase angle difference across branch $\mathrm{ij}=\theta_{i}-\theta_{j}$

$x_{i j}=$ reactance of branch $\mathrm{ij}$

$[\theta]=$ phase angle vector

$[B]$ the matrix whose elements are the imaginary parts of the nodal admittance matrix

$[P]=$ the $(\mathrm{NB} \times 1)$ node injection power vector

$\left[P_{L}\right]=$ the $(\mathrm{NL} \times 1)$ branch active power vector

$\left[B_{L}\right]=$ an $(\mathrm{NL} \times \mathrm{NL})$ diagonal matrix whose elements are branch admittance

$[A]=$ the network incidence matrix

$[K]=$ the incidence matrix of the network formed by possible lines

$\left[P_{D}\right]=$ the flow vector of possible lines

$\left[C_{D}\right]=$ the construction investment cost of possible lines

$\left|P_{L}^{\max }\right|=$ the vector of approximate current carrying capacities for existing lines

\section{REFERENCES}

[1] A.H. El-Abiad, "Power system analysis and planning," McGraw-Hill Book Company.

[2] S.K. Goswami, "Distribution system planning using branch exchange technique," IEEE Transactions on Power Systems, Vol. 12, No. 2, pp. 718-723, May, 1997.

[3] K.L. Lo and I. Nashid, "Interactive expert system for optimal design of electricity distribution systems," IEE Proc-Generation, Transmission, and Distribution, Vol. 143, No. 2, pp.151-156, March 1996.

[4] S. Jonnavithula and R. Billinton, "Minimum cost analysis of feeder routing in distribution system planning," IEEE Transactions on Power Delivery, Vol. 11, No. 4, pp. 1935-1940, October, 1996. 
[5] V. Miranda, J.V. Ranito and L.N. Proenca, "Genetic algorithms in optimal multistage distribution network planning," IEEE Transactions on Power Systems, Vol. 9, No. 4, pp. 1927-1933, November, 1994.

[6] S.M. Farrag, "New approach for planning primary distribution networks," Electric Machines and Power Systems,", USA, Vol. 21, No. 6. pp.683694, 1993.

[7] H.K. Youssef and R. Hackam, "Dynamic solution of distribution planning in intermediate time range," IEEE Transactions on Power Delivery, Vol. 3, No. 1, pp. 341-348, January, 1988.

[8] Z. Bozic and E. Hobson, "Urban underground network expansion planning," IEE Proc--Generation, Transmission, and Distribution, Vol. 144, No. 2, pp.118-122, March 1997.

[9] S.M. Farrag, "An efficient heuristic method for planning electrical networks," Engineering Research Bulletin, Faculty of engineering, Menoufiya University, Shebin El-Kom, Egypt, Vol. 21, No. 2. pp.169$181,1998$.

[10] K.J. Kim, Y.M. Park and K.Y. Lee, "Optimal long term transmission planning based on maximum principle," IEEE Transactions on Power Systems, Vol. 3, No. 4, pp. 1494-1501, November, 1988.

[11] S.M. El-Sobki, M.M. El-Metwally and M.A. Farrag, "New approach for planning high-voltage transmission networks," IEE Proceedings, Vol. 133, No. 5, pp.256-262, July 1986.

[12] X. Wang and J.R. McDonald, "Modern power system planning," McGraw-Hill Book Company, 1994.

[13] J.J. Grainger and W.D. Stevenson, Jr., "Power system analysis," McGraw-Hill Book Company, 1994. 


\title{
تلديم ويناء الثبكات الكهربائية \\ باستخدام البرمجة الخطية
}

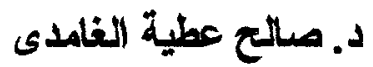 \\ الكلية التقتية بالباحة ـ الباحة ـ المملكة العزبية العمدية السعودية
}

ملخص البحث:

في هذا البحث تم إيجاد خوارزمية حل لتدعيم ويناء شبكات نقل الطاقة الكهريائية ذات التيار المتردد والضغط العالى والمتوسط ، وكذا شبكات التيكات التوزيع الأولية. وتعتمد

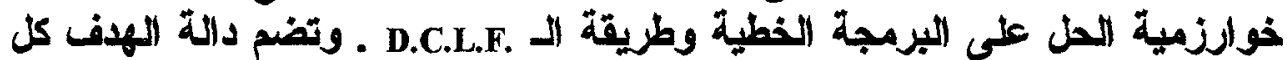

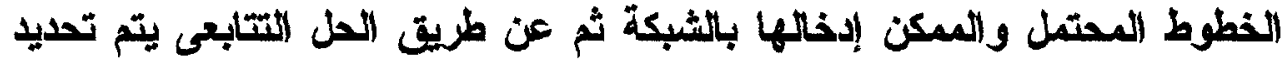

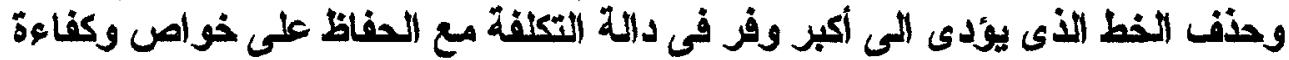
الثبكة دون إنتهاك أى من القيديود التالية:

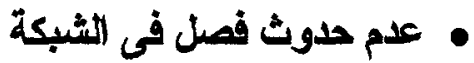

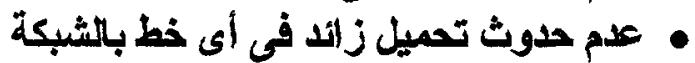

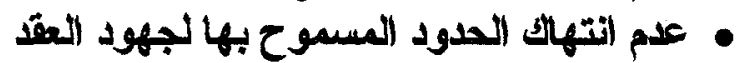

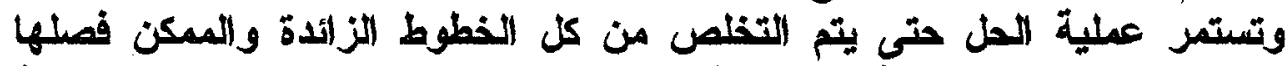

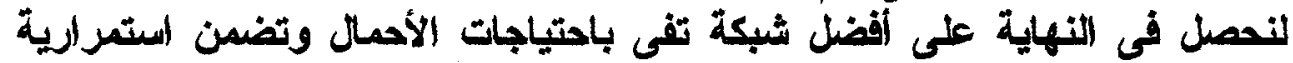
الخدمة بالكفاءة المطلوبية وباقلّ تكلفة ميكنة. وتتميز الطريقة المقترحة بالخصائص التالية: • قادرة على الحل فى حالة شبكات التونيع الأولية تمالما مثل شبكات الضنط العالى و المتوسط

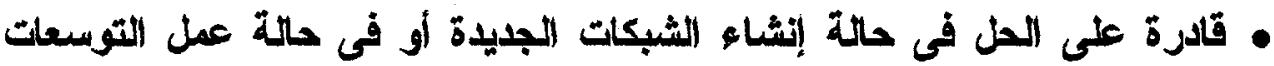

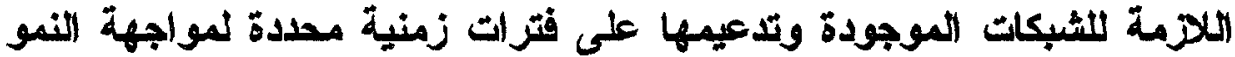
المستمر فى الأحمال

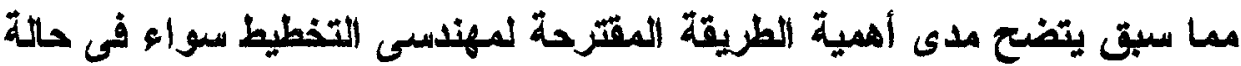

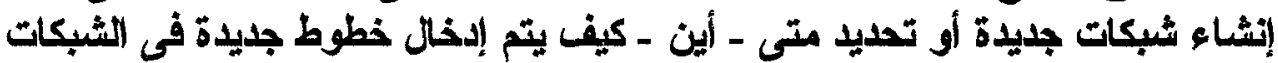

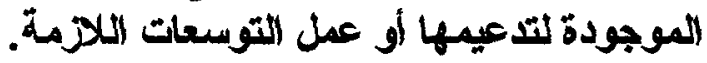

